\title{
Editorial: 50 Years of Solar Physics
}

\author{
Paul Charbonneau1 ${ }^{1}$ - John Leibacher ${ }^{2,3}$ (D) \\ Cristina Mandrini $^{4}$ (D) Lidia van Driel-Gesztelyi $^{\bullet, 6,7}$ (D) \\ Michael S. Wheatland ${ }^{8}$
}

Published online: 24 November 2016

(C) Springer Science+Business Media Dordrecht 2016

In January 1967, two solar physicists, working on opposite sides of the Iron Curtain, launched a new topical research journal called Solar Physics. Although both were headquartered in Europe, the editorial duo of Cornelis de Jager and Zdeněk Švestka (de Jager and Švestka, 1967) assembled a large and resolutely international editorial board, with 39 members spread over four continents - testimony to their intent of making Solar Physics a premier publishing venue striving to overcome geographical, political, and cultural barriers.

Chair, Editorial Board, Solar Physics: P. Charbonneau

Editors-in-Chief, Solar Physics: J. Leibacher, C. Mandrini, L. van Driel-Gesztelyi, M.S. Wheatland

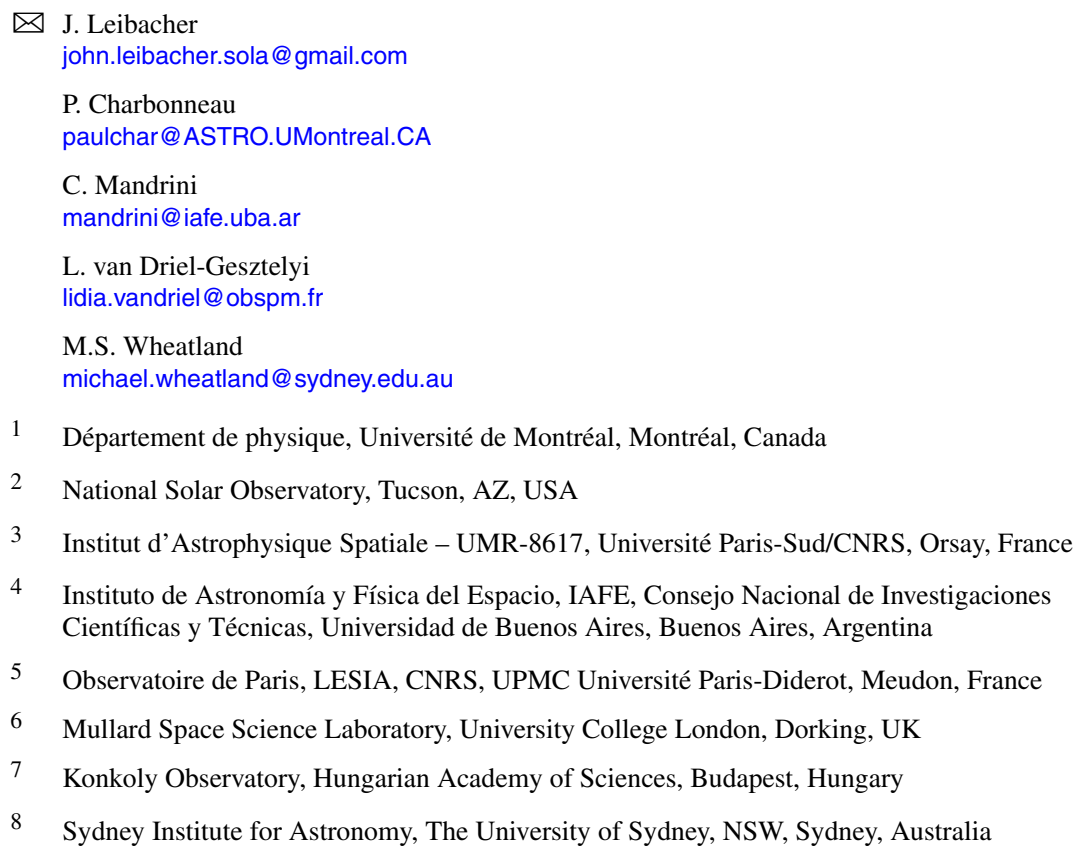


The new journal appeared in the midst of a rapid evolution in the organization of the discipline, spurred in part by the race to space (Hufbauer, 1991). It was evidently very well received, as within a few years it became the prime venue for the dissemination of solar research (see Schrijver 2016, Figure 3). Fifty years, three publishers (Reidel, Kluwer, and Springer), and 10,144 research articles totaling 133,832 printed pages later, Solar Physics is now run by a quartet of Editors-in-Chief and a duo of Associate Editors, backed by an editorial board as international as it ever was in the intervening half-century, in particular with increased representation from Asia. The journal has grown from 1009 pages in 1967 to 3870 pages in 2016 ! This growth reflects both the remarkable development of solar research worldwide, and the success of Solar Physics in supporting this development. The open, international spirit of Solar Physics remains something for all of us to serve and protect.

The first 50 years of Solar Physics have witnessed remarkable advances in our understanding of the Sun. As with other branches of astronomy, solar science has undergone a revolution driven by the access to space-based observational platforms, reaching wavelength domains otherwise blocked by the Earth's atmosphere. High-cadence observations of flares and coronal mass ejections from space, or high-precision monitoring of solar-wind properties and of total and spectral solar irradiance are now almost taken for granted, but could hardly have been imagined back in 1967. The same can be said of the science of helioseismology, which did not even exist as such in 1967, but has since pinned down the Sun's internal structure and flows to a remarkable level of detail and accuracy, even to the point that the solar neutrino problem could be safely punted back into the hands of particle physicists, and the advances have been passed along to stellar physics in the form of asteroseismology. Parallel and equally spectacular advances in computational modeling - not just raw computing power, but also algorithmic and experimental designs - have also advanced our understanding of solar phenomena. Witnessing sunspot-like magnetic structures, complete with umbrae, penumbral filaments, etc., form in a magnetohydrodynamic simulation of solar convection, or watching a simulated coronal mass ejection untwist its magnetic field as it plows through the solar wind and forms shocks, can be as inspiring and satisfying as watching the real thing; we got something right. Solar physics cannot be separated from the physics of the heliosphere, which is reflected in the growing number of articles published in Solar Physics that adopt a holistic approach. Although we are still unable to predict exactly when and where a flare or coronal mass ejection may occur, owing to our advances in understanding the initiation of solar eruptions, forecasting eruptive events and their trajectory toward Earth or other planets has advanced enormously.

Physical challenges that have been outstanding in 1967 certainly remain in 2017: first and foremost perhaps the nature of coronal heating, but also the workings of solar-wind acceleration at the base of the corona, the triggering of flares by magnetic reconnection, the magnetic-flux budget of the solar photosphere, or the detailed nature and precise location of the internal dynamo mechanism(s) underlying the solar magnetic-activity cycle. These and other substantial challenges to our understanding of the Sun and heliospheric physics will undoubtedly continue to keep future generations of solar scientists busy, fueled by revolutionary new ground- and space-based facilities. We expect the results to fill the soon-to-become-virtual pages of Solar Physics.

Volume 1 of Solar Physics opened with a frontispiece photograph of the solar corona taken in June 1966 from lunar orbit by the Surveyor-I spacecraft, a few minutes after local sunset. Within the overwhelming glow of the corona, a helmet streamer can be distinguished that extends almost perpendicular to the lunar limb. Reflecting on this photograph in the book-review pages of Zeitschrift für Astrophysik, Redman (1967) noted that while all but one of the ten research articles published in the first issue of Solar Physics were "groundbased", the photograph "... quite rightly reminded [the reader] of the possibilities of space 
research ...". Redman's prescient remark has been spectacularly vindicated in subsequent decades. Citation counts suggest the tremendous impact of observations from space. All but one of the ten most frequently cited articles from the first 50 years of Solar Physics document solar instrumentation in space: the Soft X-Ray Telescope (SXT) on Solar-A/Yohkoh (Tsuneta et al., 1991), the Large Angle and Spectrometric Coronagraph (LASCO), the Michelson Doppler Imager (MDI), and the Extreme ultraviolet Imaging Telescope (EIT) on the Solar and Heliospheric Observatory (SOHO: Brueckner et al., 1995, Scherrer et al., 1995, Delaboudinière et al., 1995), the Transition Region and Coronal Explorer (TRACE: Handy et al., 1999), the Reuven Ramaty High Energy Solar Spectroscopic Imager (RHESSI: Lin et al., 2002), the Solar Optical Telescope (SOT) on Solar-B/Hinode (Kosugi et al., 2007; Tsuneta et al., 2008), and the Atmospheric Imaging Assembly (AIA: Lemen et al., 2012) on the Solar Dynamics Observatory (SDO). The one lone ground-based top-ten article, Kopp and Pneuman (1976), describes one of the first numerical models... for the formation of a coronal helmet streamer!

What image then, in 2017, could make as prescient a forecast for the next 50 years of solar physics as that 1966 coronal photograph? This is the challenge that we now put to the community at large. Granted that the future is notoriously more difficult to predict than the past, we nevertheless invite forward-looking individuals to submit an image heralding what may await solar physics in the coming half-century, together with a brief explanatory caption (maximum 100 words). The entries will be reviewed by the editors and editorial board, and the winning entry will be displayed prominently on the Solar Physics web pages. The lucky winner will also receive a free five-year e-subscription to Solar Physics, no less. Please send your entries via email to SolarPhysicsEditors@gmail.com.

During its first 50 years, Solar Physics has published 291 volumes. The publication structure of Solar Physics has evolved over the five decades, adapting to needs of the community and requirements of the publisher. In the first year, two volumes containing 7 issues in total were published. These numbers later oscillated between 3 and 8 volumes per year that contained 8 to 14 (or even 16 in 1983 and 1985) issues, settling to a 7-volume, 14-issue model from 1994 to the end of 2013. Since 2014, Solar Physics has published 12 issues per year, forming 1 volume. During the 50 years, 54 Topical Issues were published, with 4 in the 1970s, 7 in the 1980s, 9 in the 1990s, 13 in the 2000s, and 21 in the last 7 years. These issues involved 102 Guest Editors (13 of them volunteering more than once for this role!), giving our colleagues a taste of the editorial process, and providing valuable help to the handling editor.

Together with the changes in science and in the format of Solar Physics, there have been basic changes in the mechanics of publication. The editorial from the 100th volume includes a paragraph in which the (original) editors voice a concern (de Jager and Švestka, 1985):

Please, if you cannot referee a paper within three or four weeks, send it back to our Editorial Office by return mail. If you leave for three or more weeks, do not let your mail pile on your desk, burying requests for referee reports under heaps of other matters. If you tend to forget it, kindly imagine that you yourself are the author and some other referee did receive your manuscript.

It is easy to forget that as recently as 1985 , there was no e-mail, and the editorial process involved mailing manuscripts to reviewers and waiting for reports by return mail. Things are different today: the internet has sped up the sending of manuscripts and the submission of referees' reports, but polite reminders to referees remain as important today as 50 years ago!

A significant change is to begin in January 2017: from the 51st year of the journal, the traditional issue where articles are grouped by topics will give way to a new-style publishing, 
the so-called continuous article publication (CAP) model, which means that articles are automatically assigned to a volume and issue after the proofs are corrected, i.e. articles are published online as part of the current issue that is being built, skipping the "Online First" step. The articles will have an Article Citation ID, and instead of consecutive page numbering of articles, each article will start on page number 1 . The CAP publishing model has been adopted by many leading astronomy journals, and it is time for Solar Physics to adopt this model as well. The CAP-type publishing implies that regular articles and those that are submitted to a topical issue will not be separated. For topical issues we will switch to topical collections (TCs): TC articles will be collected online under their specific topical tab, and on request, they can also be printed together as a ("spin-off") book once all of the articles have been published, subject to agreement with the publisher. Solar Physics may soon become fully electronic - another significant change to adapt to the times and needs in science publishing. We are delighted that Springer Nature has recently introduced its content-sharing initiative Sharedlt, which allows authors to swiftly and legally share their published articles.

This anniversary editorial could not conclude without acknowledging our debt and gratitude to the previous Editors-in-Chief Kees de Jager, Ždenek Švestka, Bob Howard, Oddbjørn Engvold, Jack Harvey, and Takashi Sakurai. We are literally standing on the shoulders of giants! Our work today would not be possible without our partners Associate Editors R. Howe and M. Owens, who carry on the work of our previous Associate Editors D. Banerjee and C.H. Mandrini. We particularly want do acknowledge our gratitude to K. Harvey, who for many years produced the journal's index, and to our collaborators in the management, editing, and production of Solar Physics: S. Alagesan, H. Blom, R. Cruz, V. Elango, S. Iviglia, P. Johnstone, H. Kumar, A. Peter, E. Pieren, F. Routley, J. Satten, F. Schulz, A. Simonaityte, O. Skačkauskienė, H. Stankus, L. Stonys, J. Vanagaitè, V. Vilimas, and S. van der Vaaij.

We also extend our sincere thanks to the 153 members of the international solar physics community who have served on the journal's editorial board over its first 50 years, and to the past editorial board chairs: C.J. Schrijver (2009), P. Démoulin (2010), H.S. Hudson (2011), T.G. Forbes (2012), E.W. Cliver (2013), A.M. Veronig (2014), and D.W. Longcope (2015). Finally, the scientific process as we know it would not work without the enormous contributions of the community of referees, who have contributed on the order of 40,000 reviews. One of the joys of editing is to appreciate how critically important the referees' reviews are to improving the science in the articles, not just the presentation of it; the referees' role is much more important than that of a simple "gate keeper."

Happy 50th birthday Solar Physics. Here is to many more exciting years to come, to support the ever-increasing insight into the physics of the Sun!

\section{References}

Brueckner, G.E., Howard, R.A., Koomen, M.J., Korendyke, C.M., Michels, D.J., Moses, J.D., Socker, D.G., Dere, K.P., Lamy, P.L., Llebaria, A., Bout, M.V., Schwenn, R., Simnett, G.M., Bedford, D.K., Eyles, C.J.: 1995, The Large Angle Spectroscopic Coronagraph (LASCO). Solar Phys. 162, 357. DOI. ADS.

de Jager, C., Švestka, Z.: 1967, Editorial. Solar Phys. 1, 3. DOI. ADS.

de Jager, C., Švestka, Z.: 1985, Editorial. Solar Phys. 100, ix. DOI. ADS.

Delaboudinière, J., Artzner, G.E., Brunaud, J., Gabriel, A.H., Hochedez, J.F., Millier, F., Song, X.Y., Au, B., Dere, K.P., Howard, R.A., Kreplin, R., Michels, D.J., Moses, J.D., Defise, J.M., Jamar, C., Rochus, P., Chauvineau, J.P., Marioge, J.P., Catura, R.C., Lemen, J.R., Shing, L., Stern, R.A., Gurman, J.B., Neupert, W.M., Maucherat, A., Clette, F., Cugnon, P., van Dessel, E.L.: 1995, EIT: Extreme-Ultraviolet Imaging Telescope for the SOHO Mission. Solar Phys. 162, 291. DOI. ADS. 
Handy, B.N., Acton, L.W., Kankelborg, C.C., Wolfson, C.J., Akin, D.J., Bruner, M.E., Caravalho, R., Catura, R.C., Chevalier, R., Duncan, D.W., Edwards, C.G., Feinstein, C.N., Freeland, S.L., Friedlaender, F.M., Hoffmann, C.H., Hurlburt, N.E., Jurcevich, B.K., Katz, N.L., Kelly, G.A., Lemen, J.R., Levay, M., Lindgren, R.W., Mathur, D.P., Meyer, S.B., Morrison, S.J., Morrison, M.D., Nightingale, R.W., Pope, T.P., Rehse, R.A., Schrijver, C.J., Shine, R.A., Shing, L., Strong, K.T., Tarbell, T.D., Title, A.M., Torgerson, D.D., Golub, L., Bookbinder, J.A., Caldwell, D., Cheimets, P.N., Davis, W.N., Deluca, E.E., McMullen, R.A., Warren, H.P., Amato, D., Fisher, R., Maldonado, H., Parkinson, C.: 1999, The Transition Region and Coronal Explorer. Solar Phys. 187, 229. DOI. ADS.

Hufbauer, K.: 1991, Exploring the Sun: Solar Science since Galileo, Johns Hopkins Univ., Baltimore.

Kopp, R.A., Pneuman, G.W.: 1976, Magnetic reconnection in the corona and the loop prominence phenomenon. Solar Phys. 50, 85. DOI. ADS.

Kosugi, T., Matsuzaki, K., Sakao, T., Shimizu, T., Sone, Y., Tachikawa, S., Hashimoto, T., Minesugi, K., Ohnishi, A., Yamada, T., Tsuneta, S., Hara, H., Ichimoto, K., Suematsu, Y., Shimojo, M., Watanabe, T., Shimada, S., Davis, J.M., Hill, L.D., Owens, J.K., Title, A.M., Culhane, J.L., Harra, L.K., Doschek, G.A., Golub, L.: 2007, The Hinode (Solar-B) mission: An overview. Solar Phys. 243, 3. DOI. ADS.

Lemen, J.R., Title, A.M., Akin, D.J., Boerner, P.F., Chou, C., Drake, J.F., Duncan, D.W., Edwards, C.G., Friedlaender, F.M., Heyman, G.F., Hurlburt, N.E., Katz, N.L., Kushner, G.D., Levay, M., Lindgren, R.W., Mathur, D.P., McFeaters, E.L., Mitchell, S., Rehse, R.A., Schrijver, C.J., Springer, L.A., Stern, R.A., Tarbell, T.D., Wuelser, J.-P., Wolfson, C.J., Yanari, C., Bookbinder, J.A., Cheimets, P.N., Caldwell, D., Deluca, E.E., Gates, R., Golub, L., Park, S., Podgorski, W.A., Bush, R.I., Scherrer, P.H., Gummin, M.A., Smith, P., Auker, G., Jerram, P., Pool, P., Soufli, R., Windt, D.L., Beardsley, S., Clapp, M., Lang, J., Waltham, N.: 2012, The Atmospheric Imaging Assembly (AIA) on the Solar Dynamics Observatory (SDO). Solar Phys. 275, 17. DOI. ADS.

Lin, R.P., Dennis, B.R., Hurford, G.J., Smith, D.M., Zehnder, A., Harvey, P.R., Curtis, D.W., Pankow, D., Turin, P., Bester, M., Csillaghy, A., Lewis, M., Madden, N., van Beek, H.F., Appleby, M., Raudorf, T., McTiernan, J., Ramaty, R., Schmahl, E., Schwartz, R., Krucker, S., Abiad, R., Quinn, T., Berg, P., Hashii, M., Sterling, R., Jackson, R., Pratt, R., Campbell, R.D., Malone, D., Landis, D., BarringtonLeigh, C.P., Slassi-Sennou, S., Cork, C., Clark, D., Amato, D., Orwig, L., Boyle, R., Banks, I.S., Shirey, K., Tolbert, A.K., Zarro, D., Snow, F., Thomsen, K., Henneck, R., McHedlishvili, A., Ming, P., Fivian, M., Jordan, J., Wanner, R., Crubb, J., Preble, J., Matranga, M., Benz, A., Hudson, H., Canfield, R.C., Holman, G.D., Crannell, C., Kosugi, T., Emslie, A.G., Vilmer, N., Brown, J.C., Johns-Krull, C., Aschwanden, M., Metcalf, T., Conway, A.: 2002, The Reuven Ramaty High-Energy Solar Spectroscopic Imager (RHESSI). Solar Phys. 210, 3. DOI. ADS.

Redman, R.O.: 1967, Buchbesprechungen über Solar Physics. Ed. C. De Jager and Z. Svestka. Zeit. Astrophys. 67. ADS.

Scherrer, P.H., Bogart, R.S., Bush, R.I., Hoeksema, J.T., Kosovichev, A.G., Schou, J., Rosenberg, W., Springer, L., Tarbell, T.D., Title, A., Wolfson, C.J., Zayer, I., MDI Engineering Team: 1995, The solar oscillations investigation - Michelson Doppler Imager. Solar Phys. 162, 129. ADS.

Schrijver, C.J.: 2016, Publication statistics on the Sun and the heliosphere. Solar Phys. 291, 1267. DOI. ADS.

Tsuneta, S., Acton, L., Bruner, M., Lemen, J., Brown, W., Caravalho, R., Catura, R., Freeland, S., Jurcevich, B., Morrison, M., Ogawara, Y., Hirayama, T., Owens, J.: 1991, The Soft X-ray Telescope for the SOLAR-A mission. Solar Phys. 136, 37. DOI. ADS.

Tsuneta, S., Ichimoto, K., Katsukawa, Y., Nagata, S., Otsubo, M., Shimizu, T., Suematsu, Y., Nakagiri, M., Noguchi, M., Tarbell, T., Title, A., Shine, R., Rosenberg, W., Hoffmann, C., Jurcevich, B., Kushner, G., Levay, M., Lites, B., Elmore, D., Matsushita, T., Kawaguchi, N., Saito, H., Mikami, I., Hill, L.D., Owens, J.K.: 2008, The Solar Optical Telescope for the Hinode mission: An overview. Solar Phys. 249, 167. DOI. ADS. 